Available Online : http://journals.researchsynergypress.com/index.php/jefltr/index

Journal of English as A Foreign Language Teaching and Research (JEFLTR)

ISSN ISSN 2776-4524 (Online) | 2776-4184 (Print)

Volume 1 Number 1 (2021): 25-36

\title{
Literature Survey on Teachers' and Students' Perceptions of Oral Error Correction in the EFL/ESL Classroom
}

\author{
1Lakmini Grant Siriwardana Ranpati Devayalage \\ ${ }^{1}$ Wright State University, Ohio, U.S.A
}

\begin{abstract}
Oral Error Correction (OEC) is an essential component in the English language classroom, and how teachers do it can impact students' learning in different ways. Above all, it is important for scholars to understand what teachers and students think about OEC, so that any similarities and mismatches in perceptions can be further explored and strategies for effective learning through OEC can be proposed. Thus, through this study, author aims to investigate the teachers' and students' perceptions toward OCF. With more than 20 research articles thoroughly studied, author presents a literature survey by investigating the students' perceptions regarding what types of OCF they prefer, when, and by whom (teachers and/or peers) and teachers' perceptions toward their choices of OEC. It was found that while students and teachers consider OEC to be of paramount importance for positive learning outcomes, there are also similarities and mismatches in terms of what types of OEC they prefer, by whom, and when. One outstanding mismatch was that while students like to get all their errors corrected, teachers do not consider it as pragmatic. The results also highlighted that teacher could create platforms for students to express their opinions about OEC, and they should learn about various OEC methods to choose the best ones that fit students' needs, proficiency, and the activity type.
\end{abstract}

Keywords: Oral Error Correction, Oral Corrective Feedback, Repair

This is an open access article under the CC-BY-NC license.

\section{INTRODUCTION}

Oral Corrective Feedback (OCF) or Oral Error Correction (OEC) is defined as "a response to learner utterances containing an error" (Ellis, 2006). This response comes mainly from the teacher and/or peers in the EFL/ESL classroom. While OCF is a ubiquitous phenomenon in the English language classroom, it also plays a major role in the kind of scaffolding that teachers need to provide for learners to promote constant language growth (Lyster et al, 2013). Therefore, correcting errors is essential as it helps teachers to observe the progress of the students and decide what needs to be taught further (Alamri and Fawzi, 2016).

\section{LITERATURE REVIEW}

The topic of Corrective Feedback (CF) in general has been in discussion since the 1960s (Saeb, 2017). However, the OCF has emerged as a topic of interest to scholars since 1990. In fact, most early studies had focused on the CF methods used by the teachers. For example, the recast method (reformulation of learners' erroneous utterances) has been found to be the most commonly used OEC method by the teachers (Lyster and Ranta, 1997; Ellis and Sheen, 2006). Therefore, there has been a considerable amount of research done on the impact of recasts on learner uptake (AlSurmi, 2012). Learner uptake is a student's utterance to teacher feedback; this reaction may come in two forms as "repair" and "needs- repair", in which the former means that the utterance constitutes the correct answer and the latter implies that the utterance needs repair as it is wrong (Lyster and Ranta, 1997). Lyster and Ranta's study (1997) found that recasts were the least effective in learner uptake (31\%) over negotiation of form such as clarification requests (88\%) and repetition (78\%). Moreover, Lyster (1998) found that negotiation of forms (clarification requests and elicitation of answers from students) proved more effective, resulting in immediate learner Corresponding author : Lakmini Grant Siriwardan Ranpati Devayalage lakmini.grant@gmail.com DOI: $10.31098 /$ jefltr.v1i1.439 
Journal of English as A Foreign Language Teaching and Research (JEFLTR)

Vol. 1(1), 25-36

Literature Survey on Teachers' and Students' Perceptions of Oral Error Correction in the EFL/ESL Classroom

Lakmini Grant Siriwardana Ranpati Devayalage

repair in case of lexical and grammatical errors. Studies have yet to uncover how uptake can influence Second Language (L2) learning specially in terms of students' capability to apply the repaired linguistic items in the future, successfully (Lowen, 2004).

Little attention, however, has been paid to investigate the students' perceptions regarding what types of OCF they prefer, when, and by whom (teachers and/or peers) and teachers' perceptions toward their choices of OCF. Since mismatches between students' and teachers' choices can negatively impact learning outcomes, it is important to investigate students' and teachers' perceptions toward OEC methods (Kaivanpanah et al., 2015). Such a study can be beneficial to teachers as well as students to prevent their dissatisfaction for teaching and learning, respectively. Specially, it could make the teachers aware of their students' preferences. As a result, teachers will be able to "create a more effective and involving learning environment by attending to their students' reactions and feelings" (Kaivanpanah, et al., 2015, p.90). On the other hand, if students have any misconceptions regarding OEC, teachers can correct them, which in turn will benefit the students (Saeb, 2017).

Hence, this literature survey will draw the attention of the readers to the importance of OEC first. Then, it will discuss similar and different perceptions of teachers and students about OEC in terms of how much OEC teachers like to provide and students are willing to receive, what types of CF teachers and students prefer, their preferences for immediate and delayed error correction (EC), and their ideas about teacher correction and peer correction. Finally, the survey will propose some strategies for teachers to make learning more effective through $\mathrm{OEC}$, in the discussion section.

\section{RESEARCH METHOD}

Since this is a literature survey, a qualitative analysis was done using the main findings from 29 papers. The research articles that were used to complete the survey mainly comprised of studies related to OEC perceptions of teachers and students in the EFL (Saudi Arabia, Turkey, Iran, Poland, and Australia (Japanese being the foreign language) and ESL (Canada, New Zealand, and Hawaii) settings. The analysis was done under 4 main sections which discussed the importance of knowing teachers' and students' perceptions toward OEC (1), importance of OEC (2), similar and different perceptions of teachers and students about OEC (3), and strategies to make learning more effective through OEC (4).

\section{FINDINGS and DISCUSSION}

\section{LITERATURE SURVEY}

\section{Importance of knowing teachers' and students' perceptions toward OEC.}

As stated in the introduction, knowing the perceptions of both students and teachers toward OEC strategies will factor into creating a healthy learning environment while teachers' and students' mismatches of choices and lack of understanding of their preferences hinder it. For instance, some research has highlighted inconsistencies between teachers' and students' preferences. For example, Amrhein and Nassaji (2010) found that learners preferred their teachers to correct all their errors while teachers chose to be selective in their CF. Although the study was particularly done in an L2 writing classroom in Canada, the attitudes may be transferrable to OCF. Moreover, Yoshida (2008) reported that her participants (teachers and students) preferred selfcorrection; however, teachers mostly used the recast method due to time management issues and the intention to create a supporting and less-intimidating environment for students. Further, while some teachers believe that written CF is important, they do not think OCF is necessary as they want 
Journal of English as A Foreign Language Teaching and Research (JEFLTR)

Vol. 1 (1), 25-36

Literature Survey on Teachers' and Students' Perceptions of Oral Error Correction in the EFL/ESL Classroom

Lakmini Grant Siriwardana Ranpati Devayalage

to help students speak without interruption. In this way, studies demonstrate there is a debate in the effectiveness of OCF in terms of teachers' and students' perceptions (Baz et al., 2016). Therefore, it is of paramount importance to explore their perceptions and inquire the strategies to help improve the learning outcomes for students.

\section{Importance of OEC}

While there is still research going on how and why CF affects L2 learning, there has been consistent studies to show that CF yielded better learning outcomes than no feedback (Lyster et al., 2013). For instance, referencing to research conducted by Doughty and Varela, Lyster and scholars (2013) explain how science class students aged 11 -14 who received OCF displayed short and longterm academic improvement, compared to a group that did not. They further explained that toward the end of the semester, the students were starting to self-correct before the teacher used recast (as cited in Lyster, et al., 2013). I believe this is valid evidence to say that, despite the debate as to which methods are more effective than the others, OEC is important for student learning.

Teachers also think that OEC is important because students need to receive information about their errors to prevent the occurrence of errors in the future (Tomczyk, 2013). In other words, they find that OEC is essential to minimize the intended number of fossilized errors. Also, teachers point out that, they should make the students aware of their errors, as it will motivate the students to work on their errors and subsequently make a progress (Tomczyk, 2013). Most teachers (70\%) even stated that they feel like they cheated their students, if they ignored students' errors (Baz et al., 2016). It implies that teachers consider OEC as one of their major responsibilities.

Similarly, students feel that OEC is essential because they want to get rid of their errors, before the errors become part of their habits (Tomczyk, 2013). Among research studies conducted to explore students' perceptions about OEC, many studies confirm that students like to receive OEC (Kaivanpanah et al., 2015; Saeb, 2017)). It is evident that the purpose of both students and teachers are similar in that, they do not want their errors to become fossilized or permanent. This necessity seems to be consistent even across different nationalities and males and females. For example, in a study conducted with ESL students across different nationalities (Hong Kong, Japan, Korea, Taiwan, Vietnam), all students except Koreans expressed their extreme willingness to get corrected, even more than what they received at that moment (Chenoweth et al., 1983). According to those students, error correction (EC) by the teachers largely affects the improvement of language although it sometimes makes them feel embarrassed. At the same time, ignoring an error by the teacher was totally rejected by the students (Alamri \& Fawzi, 2016). Thus, both teachers and students accept that correcting oral errors is important, although teachers reveal differences in their perception of how much errors should be corrected.

\section{Similar and different perceptions of teachers and students about OEC.}

Although teachers and students agree on the importance of OEC, similar as well as totally different views about how much, how, and when errors should be corrected, and who should correct errors, were observed.

\subsection{How much OEC is preferred?}

First, while most students agreed that all their errors need to be corrected, teachers disagreed with that idea. For instance, in Saeb's study (2017) which was done with 68 EFL high school students of a lower intermediate proficiency in Iran, students thought that when teachers correct all their errors, it makes them aware of their language problems and prevents them from repeating errors. However, $62.9 \%$ of teachers believed that they should correct only those errors that interfere with the meaning of communication, as they believe that the main purpose of language is nothing but communication (Saeb, 2017). Therefore, the teachers want to ensure that 
Journal of English as A Foreign Language Teaching and Research (JEFLTR)

Vol. 1(1), 25-36

Literature Survey on Teachers' and Students' Perceptions of Oral Error Correction in the EFL/ESL Classroom

Lakmini Grant Siriwardana Ranpati Devayalage

students speak with minimum distraction. Similarly, studies (Tomczyk, 2016; Alamri and Fawzi, 2016) confirmed that, teachers 'often' or 'usually' correct errors. In Alamri and Fawzi's study (2016), the research participants were students and teachers from Yanbu University in Saudi Arabia. The scholars reported that, on contrary to the students' need for being corrected for all the errors, teachers preferred otherwise because they are either concerned about improving students' ability to convey meanings or lack knowledge of the EC methods. Also, the teachers from Brown's (2009) and Lasagabaster and Sierra's studies (2005) revealed that correcting each error will interrupt the flow of communication, make students anxious, and will affect students' level of confidence. Time management has also been pointed out as a reason for teachers' decision not to correct all the errors (Yoshida, 2008). This common stance of the teachers does not mean they do not see the importance of correcting errors. It seems that they have valid reasons for doing so.

Thus, instead of correcting all errors, teachers in most studies revealed that they are selective of the errors that they correct. Most studies (Saeb, 2017; Baz et al., 2016) highlighted that teachers are determined to correct errors that disturb comprehensibility of the speech. For instance, 50\% of interviewed Turkish instructors at a state university, in Baz et al.'s study (2016) held this view. In fact, according to Isaacs \& Trofimovich (2012), lexical and phonological errors are the ones that directly inhibit native speakers' comprehensibility of the speech of L2 learners, regardless of proficiency levels. So, this idea of the teachers appears to be plausible. Further, all the student teachers at Gazi University in Ankara, Turkey, in Ozmen and Aydin's study (2015) stated that they like to correct only repetitive errors of a student or errors that are frequently committed by the majority of students. For example, one student teacher stated that if she hears the same error for few times from one student or from many students, she will correct it as a common error without pointing out at students individually. Thus, by correcting only selected types of errors, teachers intend to boost students' motivation and confidence, create an opportunity for learner autonomy, and stop fossilization (Ozmen and Aydin, 2015).

Another difference observed between teachers' and students' perceptions is that while students put a lot of emphasis on grammar correction, teachers seemed to be moderate about it (Chenoweth et al., 1983). Turkish student teachers in Ozmen and Aydin's study (2015) stated that grammatical errors can be overlooked in speaking, because according to them, students get rid of their grammatical errors gradually, with the natural order of acquisition. It means that teachers do not have to correct grammatical errors extensively if the student's proficiency level is beyond understanding the particular grammatical rules, which I also agree with. This perception is in parallel with the studies by Kim and Han (2007) and Mackey et al. (2000) which report that learners produce more effective repair on lexical and phonological errors than grammar errors. According to Saeb (2017), however, students' priority for grammar (especially EFL students) may have been caused by the fact that these students are forced to perceive language as "a system of rules" rather than "a means of communication which is best acquired procedurally through usage and practice" (p. 14). I can relate to this idea because growing up in Sri Lanka, I learned English mostly in relation to grammar where grammar rules were extensively taught, and most students were encouraged to apply the rules through rote.

Next, proficiency level of the students is also a consideration of some teachers when deciding the amount of CF, they should give to students. For example, it was indicated that teachers wanted to correct elementary level students more frequently than others because if they ignore those errors, students will learn it "in a wrong way", assuming they did not make errors at all (Ozmen and Aydin, 2015). Also, Saudi Arabian teachers said that they would give more CF to fluency errors (errors that inhibit meaning) made by low-proficiency students and more CF to accuracy errors (errors in grammar and vocabulary that do not necessarily obstruct meaning) made by highproficiency students (Alamri and Fawzi, 2016). In their point of view, it will help low-proficiency students to develop meaningful communication because they will not understand corrections of 
Journal of English as A Foreign Language Teaching and Research (JEFLTR)

Vol. 1 (1), 25-36

Literature Survey on Teachers' and Students' Perceptions of Oral Error Correction in the EFL/ESL Classroom

Lakmini Grant Siriwardana Ranpati Devayalage

accuracy errors. However, high proficiency students, whose fluency is also high, will understand corrections of accuracy errors (Alamri and Fawzi, 2016).

Some teachers also consider the activity type when deciding the amount of OEC. Some Turkish teachers indicated that they would correct the errors in accuracy-based activities more frequently than in fluency-based activities (Ozmen and Aydin, 2015). The reason is that, in accuracy-based activities, teachers' goal is to give opportunities for students to practice correct target language forms. So, if the students commit any errors regarding 'forms', teachers must communicate that to students. Nonetheless, the idea behind fluency- based activities is to encourage students to speak as much as they can, without letting them worry too much about errors.

In fact, it is obvious that correcting all the errors will not have a positive impact on learning. Even Lyster and Ranta's study (1997) showed that out of all the turns of CF, less than one third led to learner repair. On the other hand, it is the teacher who is supposedly more knowledgeable about the types of errors that need more attention to improve communication skills. So, due to this understanding of the teachers, it can be assumed that they are selective of the errors they must correct. However, the mismatch between the teachers' and students' perceptions implies that it is mandatory for the teachers to make students aware of "what constitutes effective error correction" through informative discussions and conferences (Saeb, 2017).

\subsection{What types of OCF do teachers and students prefer?}

There are 6 different types of CF that Lyster \& Ranta (1997) identified and a few more proposed by Sheen and Ellis (2011). From Lyster \& Ranta's study (1997), first one is 'explicit correction', in which the teacher clearly indicates that the student's utterance is wrong and then gives the correct form. Second is 'recast' where the teacher provides the student with the correct form, without necessarily indicating that the said utterance is wrong. Next, there are four other forms that aim at eliciting a self-correction from the student. First is 'clarification request' where the teacher says a phrase like, 'what did you say?' or "I don't understand" to elicit the answer from the student. Second is 'meta- linguistic feedback'; teacher provides some grammatical metalanguage that refers to the error to help the student self-correct (e.g. Is that how we use the past tense of "go"?). Third, through 'elicitation', teacher gives the student an opportunity to self-correct by allowing him/her to fill in a blank, using a phrase like, 'It's a ......................' or asking a question such as "How do we say that in English?". 'Repetition' is the final CF type aiming at self-correction; it occurs when the teacher repeats the erroneous utterance of the student with an adjusted intonation. In addition to those types, Sheen \& Ellis (2011) proposed CF types such as explicit correction with meta-linguistic explanation and meta-linguistic clue (similar to meta-linguistic feedback) and paralinguistic signal (an attempt to non-verbally elicit the correct form from the learner). However, it is difficult to say that one type is completely implicit and the other is completely explicit. Instead, we could say that CF types exist in a continuum, and that implicitness or explicitness depends on the way each teacher handles them (Lyster et al., 2013).

Having discussed different types of CF, it is now important to explain how students' and teachers' preferences for them were different. In the studies of Saeb (2017), Tomczyk (2013), Baz, et al., (2015), students wanted teachers to do explicit correction with meta-linguistic explanation. For instance, in Saeb's study (2017), students pointed out that for effective learning, they want to know that an error was committed and receive information from the teacher as how to correct it, with some explanations. Similarly, students claimed that they would like the teacher to introduce to them a rule or definition related to the error committed, contrary to the teachers' beliefs in elicitation methods (Tomczyk, 2013). We already discussed that students have a deep inclination to get all their errors corrected by the teachers, and the above studies prove it and highlight that the students solely put the responsibility of error correction on the teacher. 
Journal of English as A Foreign Language Teaching and Research (JEFLTR)

Vol. 1(1), 25-36

\section{Literature Survey on Teachers' and Students' Perceptions of Oral Error Correction in the EFL/ESL} Classroom

Lakmini Grant Siriwardana Ranpati Devayalage

However, in Yoshida's study (2008), students learning Japanese in an Australian university preferred self-correction methods such as elicitation and clarification over recasts, as the students liked to find answers on their own. In contrast, some students thought that elicitation induces a sense of nervousness and anxiety in them (Saeb, 2017; Tomczyk, 2013). It could be assumed that students with advanced proficiency prefer the challenge of self-correcting. For instance, the high proficiency EFL students in Iranian private institutes gave stronger support for elicitation methods while low proficiency students were more supportive of meta-linguistic feedback (Kaivanpanah et al., 2015).

When it comes to teachers, most of their opinions were quite different from most of the students discussed above. Some of the teachers believed that explicit EC increases students' anxiety as it involves announcing of the fact that an error has been committed. Moreover, they thought that meta-linguistic explanation is needed only in cases where there is a recurring grammatical error (Tomczyk, 2017). Instead, despite some students' dislike for elicitation, most teachers showcased that, self-correction types such as elicitation, repetition, and clarification requests create learner autonomy, by reducing students' reliance on the teacher and giving them an opportunity to monitor and locate their own errors (Saeb, 2017; Tomczyk, 2013). Further, they said that self-correction types imply 'active-engagement' of the students in the learning process (Saeb, 2017; Tomczyk, 2013).

As per the similarities between students' and teachers' perceptions, a study in Saudi Arabia revealed that there is a tendency for both teachers and students to like recasts. According to Alamri \& Fawzi (2016), tertiary level Saudi Arabian teachers may lack knowledge of effective ways to correct their students; consequently, they frequently use types like recast over others. As a result, students get less or no exposure to other CF types, and they naturally tend to like the existing ones. Even (Kaivanpanah et al., 2015) highlighted that students' general preference for recast may be due to their unfamiliarity with other types. On the contrary, in Yoshida's study (2008), both teachers and students preferred the elicitation techniques; however, due to teachers' concern for time and creating a less threatening environment for students, teachers mostly opted to use recast in classrooms.

Apart from these general perceptions, some teachers believed that they must switch their CF depending on the students' proficiency level. For example, the student teachers in the study of Ozmen \& Aydin (2015) expressed that they would use implicit CF such as recast for low proficiency students, elicitation for intermediate students, and explicit correction for both intermediate and upper-intermediate students. Similarly, Iranian teachers in the study of Kaivanpanah et al., (2015) claimed that, elicitation is more useful for advanced learners. Meta-linguistic clue has also been pointed out as a type only suitable for high proficiency students as low proficiency students do not know language rules sufficiently to understand the clue and produce the correct answer (Saeb, 2017). We can see a close connection between these teachers' perceptions and the students with advanced proficiency in Yoshida's study (2008) who claimed that they needed the chance to selfcorrect.

Then, some teachers also pointed out that they would choose CF type based on the activity type. One Turkish teacher told in an interview, "The oral feedback I give depends on the task", confirming the finding from research by Lyster \& Mori (2006), that instructional setting should be taken into consideration when giving CF. Some student teachers in Turkey also said that they use explicit correction for fluency-based activities as they believed that pronunciation plays "a key role" in being able to communicate with native speakers (Ozmen and Aydin, 2015). Also, they said they would use both explicit correction and elicitation for accuracy- based errors.

In a nutshell, while there are a few similarities, there are more differences between the perceptions of the teachers and students, in terms of the type of feedback students would like to receive, especially explicit OEC being most students' favorite while teachers are more open to recast (to create a supporting learning environment) and elicitation (to facilitate student autonomy). It is 
Journal of English as A Foreign Language Teaching and Research (JEFLTR)

Vol. 1 (1), 25-36

Literature Survey on Teachers' and Students' Perceptions of Oral Error Correction in the EFL/ESL Classroom

Lakmini Grant Siriwardana Ranpati Devayalage

also interesting to know that some teachers take into consideration the proficiency and the activity type in deciding the CF type that they will use. I believe that it is an effective strategy, as needs of the students, proficiency level, and the objective of a lesson should be deciding key factors in the type of feedback that students should receive.

\subsection{Who should correct errors?}

While the teacher is considered the most reliable figure in the classroom to disseminate knowledge to students and give CF, in the present, especially in the U.S., peer CF is frequently used in language classrooms. Therefore, it is worth reporting teachers' and students' beliefs about teacher $\mathrm{CF}$ and peer $\mathrm{CF}$ found in these studies. When it comes to the preference for the ideal person to correct errors, without doubt, most EFL students believed that it is the teacher who must do OEC; teacher is seen as a "competent, non-erring, and ultimate authority" (Tomczyk, 2013, p. 927). The same thought is shared by the students in Saeb's (2007) and Zacharias's (2007) studies. Students also claimed that if the errors are corrected by the peers, they can contain mistakes due to the inadequate knowledge of the students (Saeb, 2017). Moreover, according to Katayama (2007), Japanese EFL students highly trusted teachers' correction for pronunciation errors in the absence of native students. They strongly believed that it is only the teacher who will have native-like pronunciation. So, EFL students seem to deeply trust their teachers for correcting pronunciation errors. In another study from Turkey, $80 \%$ of EFL students stated that it is the instructor who 'improves' their English and is 'trustable' in error correction (Baz et al., 2015. p. 61). Moreover, in most EFL countries such as Iran and Saudi Arabia, teacher plays a dominant role. For example, in Iran, it was said that even in conversational activities, students direct their gaze only towards the teacher as s/he is considered the center of attention; therefore, students believe that teacher is the best person to correct errors (Kaivanpanah et al., 2015). This conception may have caused them to be opponents of peer-correction. It is clear that the teacher-centered education in some cultures directly affects students' choice in teacher and peer correction.

Having discussed students' strong preference for teacher CF and reasons for it, it is also crucial to highlight some mismatches noticed between teachers' and students' perceptions regarding peer CF. One mismatch can be noticed in a study conducted in Iran (Kaivanpanah et al., 2015). Although those EFL students firmly agreed with teacher CF, they did not completely reject peer $\mathrm{CF}$ because students claimed to have good relationships with their classmates. Nevertheless, teachers expressed only negative aspects of peer CF because they had a misconception that peer $\mathrm{CF}$ will humiliate students and will generate a fear of being judged (Kaivanpanah et al., 2015). This misunderstanding of the teachers will probably minimize the effectiveness in learning and deny students of a learning opportunity they like. Another contrasting situation is that, in another study from Poland, EFL students did not like peer CF at all whereas teachers supported it. Students thought that their friends may not be competent enough to correct their errors (Tomczyk, 2013). Even in Hyland's study (2000) in a New Zealand University which mostly focused on peer feedback on writing, students were more positive toward peer feedback on developing their writing process, whereas teachers were critical about peer reviewing for written drafts.

There was one study concerning the attitudes of students (from different nationalities) about CF of native speaker friends in an ESL context, Hawaii (Chenoweth et al., 1983). They had an extremely positive view about it, and they even expressed their willingness to get corrected more than what they received at that moment (Chenoweth et al., 1983). Looking at this finding, it can be assumed that, in EFL contexts, students' lack of reliance on peer CF may have arisen from the students' belief that their non-native friends are not proficient and competent enough in their target language to provide correct forms.

Thus, students select teacher as the best person for EC. Specially, in most EFL classrooms, teacher is considered as the most reliable resource for EC. On the other hand, a few studies also show some mismatches between teachers' and students' preference for peer CF. Moreover, ESL 
Journal of English as A Foreign Language Teaching and Research (JEFLTR)

Vol. 1(1), 25-36

Literature Survey on Teachers' and Students' Perceptions of Oral Error Correction in the EFL/ESL Classroom

Lakmini Grant Siriwardana Ranpati Devayalage

students seem to be very positive about peer CF from native speaker friends. The findings imply that, although teacher CF is prominent, peer CF should not be wiped out of the classroom because they also constitute intended benefits, and some students like it. Specially, as pointed out by Lyster \& Ranta (1997), when lower-intermediate students do not understand the teacher's feedback, mostly implicit, peer feedback can work as an alternative or an 'antidote'. I also believe that, it is the teachers' responsibility in EFL contexts to explain to students that the peers are also capable of correcting errors, which can also facilitate students' confidence.

\subsection{When should errors be corrected?}

There are two different types of timing identified to provide CF; those are immediate and delayed EC. Brown put forward that "Learners think that a quality of effective teachers is to be able to correct oral errors immediately" (as cited in Lyster et al., 2013, p.7). However, in these studies, most teachers and students showed their support for delayed EC due to several reasons. First, teachers thought that they should not interrupt the students' flow of speech through immediate correction (Tomczyk, 2013). They also believed that immediate correction will undermine students' self-esteem in front of their peers (Kaivanpanah et al., 2015). Similarly, some students pointed out its benefits, by highlighting drawbacks of immediate OEC. For instance, they said that immediate EC makes them forget their purpose of speaking and feel stressed with the feeling that they are unable to perform in the target language. Instead, they said that delayed EC allows them to finish their speech, drawing their attention to the error only at the end of utterances (Tomczyk, 2013).

A few teachers stated that they are also concerned about the activity type, students' proficiency level, and the focused error types, when making decisions regarding the timing of OEC. For instance, teachers said that they would immediately correct pronunciation and vocabulary errors (with implicit methods), but in the presence of low proficiency and anxious students, they would use delayed correction (with meta-linguistic techniques), particularly for grammar errors (Kaivanpanah et al., 2015). Also, teachers believed that delayed EC best fits fluency activities as a way of motivating students' speech (Ozmen \& Aydin, 2015).

In contrast to teachers' general favor for delayed EC, one study from Iran revealed that teachers still choose immediate OEC whereas students are not comfortable with it (Farahani \& Salajegheh, 2013). The author explained that this may be the effect of the teachers' favor for audio lingual method, which is based on the habit formation theory of the Behaviorist approach (Farahani \& Salajegheh, 2013). Audio-lingual method indicates that, repeated behavioral patterns become imprinted in memory. So, when students continuously repeat the correct form after the teacher, (through recast) they will be able to remember it well. It is clear there is a strong validation for delayed EC from teachers as well as students; however, teachers from one study in Iran seem to be proponents of immediate EC. Also, a few teachers chose to switch between the two options due to the concern for learners' proficiency level and the activity type, which seems like a more accurate approach.

When considering the whole section called, "Similar and different perceptions of teachers and students about OEC", some discrepancies could be noticed between teachers' and students' perceptions, specially related to the amount of errors that should corrected, the methods of OEC they prefer, and their perception toward peer/teacher feedback. They obviously can lead to negative effects on learning (Kaivanpanah et al., 2015). Therefore, it is essential for the EFL/ESL teachers (especially those who are new to the field) to know how to make learning more effective through OEC.

\section{DISCUSSION}

\section{How to make learning more effective through OEC?}


Journal of English as A Foreign Language Teaching and Research (JEFLTR)

Vol. 1 (1), 25-36

\section{Literature Survey on Teachers' and Students' Perceptions of Oral Error Correction in the EFL/ESL} Classroom

Lakmini Grant Siriwardana Ranpati Devayalage

Due to some mismatches between teachers' and students' perceptions about OEC, it is worth discussing what constitutes effective OEC. In fact, the answer is, there is no 'one' particular method. Ellis, for example, put forward that "it may be fundamentally mistaken to look for the most effective type of strategy" (Ellis, 2012, p. 263). It is because of the complex nature of each classroom in terms of the context (EFL/ESL), the type of the course (speaking/ grammar), and the complex nature of individual students in terms of proficiency level, age, and affective factors such as motivation and anxiety. Thus, the section will discuss a few possible strategies that teachers can bring into classroom to create better learning opportunities for students.

First and foremost, to make learning more effective, it is essential for the teachers to know their students' preferences about OCF. Therefore, it is the teachers' responsibility to provide enough opportunities for the students to discuss their preferences for OEC (Kaivanpanah et al., 2015). There are numerous benefits of this. First, by getting to know about students' preferences, teachers can implement CF methods students like, if those are suitable. At the same time, if teachers find out that students are critical about CF types they use, but which are really beneficial for students, teachers can explain to students that they use the particular types with a reasonable purpose. For example, from the earlier discussion, we understood that most students in general have a great favor for explicit correction which may not be effective all the time. Even the output hypothesis of de Bot (1996), explains that L2 learners benefit more from being pushed to retrieve target language forms than from merely hearing the forms in the input, because retrieval and production process can strengthen associations in memory. That means, prompts such as elicitation, clarification requests, and repetition could be more facilitative for learning. Hence, through discussions, teachers can educate their students of the particular benefits of selfcorrection. Moreover, if the students have any misconceptions regarding OEC, teachers can help the students get rid of those during discussion sessions (Saeb, 2017). For example, teachers must tell their students that correcting each error is not practical as all of them do not necessarily lead to repair and that may interrupt the flow of speech. Thus, it is important that students and teachers discuss their opinions with each other open-mindedly. This awareness of both teachers and students makes the learning more effective and meaningful and builds a healthy student-teacher relationship.

Second, it is important for the teachers to have substantial knowledge about the advantages and disadvantages of each type of $\mathrm{CF}$, delayed and immediate EC, and peer $\mathrm{CF}$ and teacher $\mathrm{CF}$, in relation to their student groups. If they are novice teachers, they can gain knowledge from research and from well-experienced teachers. It is important for them to know that any CF method may constitute pros and cons depending on the situation. For example, if the teachers overuse recast, students will then rely on the teachers to provide the correct form all the time. Consequently, students will stop noticing the CF, and will lose their confidence for self-monitoring and effortful generation of the target language (Lyster et al., 2013). So, it could be a good idea to limit recast to correct only one or a few linguistic features (Lyster \& Ranta, 2007). Yet, recast could be well suited to a communicative classroom as they tend not to interrupt the flow of communication, keep students' attention focused on meaning, and provide scaffolds (Lyster et al., 2013). Therefore, this enriched knowledge of the teachers about OEC and its application can make leaning more effective for the students.

Third, it is important for the teachers to experiment various types of CF, (rather than follow the same ones) and then decide which types are more effective than others since "one size does not fit all" (Ammar and Spada, 2006, p. 566). "One size does not fit all" because as mentioned earlier, different student groups constitute characteristics brought from various cultures, and this diversity requires teachers to adopt multiple OEC methods (Lyster and Mori, 2006). Therefore, teachers have to consider factors such as learner proficiency, age, and affective factors (motivation and anxiety), when deciding how to, when to, and who is supposed to correct errors. Not only the nature of learners, but also the nature of the activity, classroom setting, and the focused error types should 
Journal of English as A Foreign Language Teaching and Research (JEFLTR)

Vol. 1(1), 25-36

Literature Survey on Teachers' and Students' Perceptions of Oral Error Correction in the EFL/ESL Classroom

Lakmini Grant Siriwardana Ranpati Devayalage

be taken into consideration prior to making decisions about OEC. Hence, the best thing is to experiment various methods of $\mathrm{CF}$ and then choose the best ones that tally with learner differences and teaching goals. To conclude, by having extended discussions with students, gaining a substantial knowledge about OEC, experimenting different CF methods and by considering differences in learners and teaching goals before doing OEC, teachers could make learning more effective for the learners.

\section{CONCLUSION}

The most noticeable mismatches between teachers' and students' perceptions are as follows. The students showed a great dependence on the teachers as most of them expressed their need to have all their errors corrected and get their errors corrected through explicit correction. In contrast, most teachers disagreed with the fact that all errors must be corrected, and they considered self-correction types such as elicitation and clarification request to be more beneficial. This suggests that teachers are trying to adopt a more student-centered approach to teaching whereas most students still seem to expect everything from the teacher and believe in teachercentered education.

It should be noticed that the above mismatches can lead to negative outcomes in learning (Kaivanpanah et al., 2015). For example, when students do not get corrected as they expect, they will be frustrated and may think teachers ignored them. At the same time, as in the Iranian study (Kaivanpanah et al., 2015), if the teachers assume that their students do not like peer CF, whereas in real, the students like peer $\mathrm{CF}$, it may sometimes demotivate students and generate unpleasant feelings in students about the teacher. Therefore, as suggested in the discussion section, it is necessary for the teachers to have enough discussions with students to learn students' preferences and inform students about teachers' preferences.

Apart from that, some perceptions of the teachers are conducive to learning. For example, some teachers reported that they consider students' proficiency level and the type of the activity before they decide how and when to correct errors (Ozmen \& Aydin, 2015). In that light, some teachers stated that, they would use elicitation for advanced students and recast for low-proficiency students (Kaivanpanah et al., 2015). Although, it was generally believed that teachers in Saudi Arabia and Iran may not know effective ways to correct students, at least some teachers seem to have deviated from this general pattern which could be considered as a positive trend in EFL contexts (Saeb, 2017).

As per the implications, it can be delineated that most teachers would like to promote communicative language teaching whereas some others still value behaviorist approach. Those who appreciate communicative teaching promote learner autonomy by helping the students to locate their own errors and develop language skills through CF methods like elicitation. On the other hand, some teachers found benefits of audio-lingual method, a method which derived from the behaviorist approach (Farahani \& Salajeghei, 2015). Those teachers believe that immediate correction (through recast) followed by students' drills help students retain the correct form in their memory for a long time. The fact that some teachers tend to consider the proficiency level of the students before they decide how to and when to correct students show that they are with the dialogical tradition emerged in the 1990s' which advocated that individual differences have to be considered in SL acquisition. I also believe that communicative language teaching constitutes more benefits especially in OEC, but aspects such as audio-lingual methods and drills cannot be fully discarded, especially with phonological errors. The best way is to experiment various methods and then apply more effective ones in classrooms.

As per the differences observed between EFL and ESL contexts, it is visible that EFL students have more concern for grammar than ESL learners. According to Schulz (as cited in Lyster et al., 2013), it may be due to the traditional ways in which foreign languages are taught and tested, 
Journal of English as A Foreign Language Teaching and Research (JEFLTR)

Vol. 1 (1), 25-36

Literature Survey on Teachers' and Students' Perceptions of Oral Error Correction in the EFL/ESL Classroom

Lakmini Grant Siriwardana Ranpati Devayalage

beliefs passed on about the usefulness of grammar study, and the fact that classroom is the only place to improve grammar. Therefore, students in EFL contexts should be made aware that, to improve fluency, grammar correction is important, but not compulsory all the time. Also, teachers should give them enough motivation to 'practice' speaking as much as they could without worrying too much about grammatical errors (Saeb, 2017). As a final note, I would like to highlight Allwright's (1975) recommendation that both teachers and researchers should explore more not only on particular types of CF (recast, elicitation), but also how each of these types can be used and modified to achieve their objective in the lesson.

\section{LIMITATION \& FURTHER RESEARCH}

The study is a literature survey which involved only the studies done by other scholars. I would like to extend this investigation by conducting a research study in in the United States with my ESL students. Since these students come from different nationalities (Chinese, Indian, Japanese, and Saudi Arabian), through such a study, I would be able to understand their various perceptions toward OEC, which may have been influenced by their education system back home. Researching on their perceptions will be resourceful for me and other ESL teachers when making decisions about OCF. I would also like to explore more studies done in different ESL and EFL contexts to see if there are differences and similarities between the perceptions of teachers and students depending on the geographical locations.

\section{REFERENCES}

Alamri, B., \& Fawzi, H. H. (2016). Students' preferences and attitude toward oral error correction techniques at Yanbu University College, Saudi Arabia. English Language Teaching, 9 (11), 59.

Allwright, R. L. (1975). Problems in the study of the language teacher's treatment of learner error. In M. K. Burt \& H. C. Dulay (Eds.), On TESOL '75: New directions in second language learning, teaching and bilingual education. Washington, D.C.: TESOL Inc.

Al-Surmi, M. (2012). Learners' noticing of recasts of morpho-syntactic errors: Recast types and delayed recognition. System, 40(2), 226-236.

Amrhein H.R., \& Nassaji H. (2010) Written Corrective Feedback: What do students and teachers prefer and why? Canadian Journal of Applied linguistics, 13, 95 - 127.

Baz, E. H., Balçıkanl, C., \& Cephe, P. T. (2016). Perceptions of English instructors and learners about corrective feedback. European Journal of Foreign Language Teaching, 1-15.

Brown, A. (2009). Students' and teachers' perceptions of effective foreign language teaching: A comparison of ideals. The Modern Language Journal. 93(1), 46-60.

Chenoweth, N. A., Day, R. R., Chun, A. E., \& Luppescu, S. (1983). Attitudes and preferences of ESL students to error correction. Studies in Second Language Acquisition, 6(1), 79-87.

De Bot, K. (1996). The psycholinguistics of the output hypothesis. Language Learning 46(3), 529555

Ellis, R. \& Y. Sheen (2006). Reexamining the role of recasts in second language acquisition. Studies in Second Language Acquisition 28(4), 575-600.

Ellis, R. (2006). Researching the effects of form-focused instruction on L2 acquisition. AILA Review. 19,18-41.

Ellis, R. (2012). Language teaching research and language pedagogy. Oxford: Wiley Blackwell.

Farahani, A. A. \& Salajegheh, S. (2015). Iranian EFL teachers' and learners' perspectives of oral error correction: Does the timeline of correction matter? Latin American Journal of Content and Language Integrated Learning, 8(2), 184-211. 
Journal of English as A Foreign Language Teaching and Research (JEFLTR)

Vol. 1(1), 25-36

Literature Survey on Teachers' and Students' Perceptions of Oral Error Correction in the EFL/ESL Classroom

Lakmini Grant Siriwardana Ranpati Devayalage

Isaacs, T. \& P. Trofimovich (2012). Deconstructing comprehensibility: Identifying the linguistic influences on listeners' L2 comprehensibility ratings. Studies in Second Language Acquisition. 34(3), 475-505.

Kaivanpanah, S., Alavi, S. M., \& Sepehrinia, S. (2015). Preferences for interactional feedback: Differences between learners and teachers. The Language Learning Journal, 43(1), 74-93.

Katayama, A. 2007. Students' perceptions toward corrective feedback to oral errors. Asian EFL Journal, 9(4), 289-305.

Kim, J. \& Z. Han (2007). Recasts in communicative EFL classes: Do teacher intent and learner interpretation overlap? In A. Mackey (ed.), 269-297.

Lasagabaster, D., \& J. M. Sierra (2005). Error correction: Students' versus teachers' perceptions. Language Awareness, 14, 112-127.

Loewen, S. (2004). Uptake in incidental focus on form in meaning-focused ESL lessons. Language learning, 54(1), 153-188.

Lyster, R. (1998). Negotiation of form, recasts, and explicit correction in relation to error types and learner repair in immersion classrooms. Language learning, 48(2), 183-218.

Lyster, R., \& Mori, H. (2006). Interactional feedback and instructional counterbalance. Studies in Second Language Acquisition, 28(2), 269-300.

Lyster, R., \& Ranta, L. (1997). Corrective feedback and learner uptake. Studies in second language acquisition, 19(1), 37-66.

Lyster, R., Saito, K., \& Sato, M. (2013). Oral corrective feedback in second language classrooms. Language teaching, 46(1), 1-40.

Mackey, A., S. Gass \& K. McDonough (2000). How do learners perceive interactional feedback? Studies in Second Language Acquisition. 22(4), 471-497.

Ozmen, K. S., \& Aydın, H. Ü. (2015). Examining student teachers' beliefs about oral corrective feedback: Insights from a teacher education program in Turkey. Australian Journal of Teacher Education, 40(12), 10.

Saeb, F. (2017). Students' and teachers' perceptions and preferences for oral corrective feedback: Do they match? International Journal of Applied Linguistics \& English Literature, 6(4), 3244.

Sheen, Y. \& R. Ellis (2011). Corrective feedback in language teaching. In E. Hinkel (ed.), Handbook of research in second language teaching and learning, Vol. 2. New York: Routledge, 593-610.

Tomczyk, E. (2013). Perceptions of oral errors and their corrective feedback: Teachers vs. students. Journal of Language Teaching \& Research, 4(5), 924-931.

Yoshida, R. (2008). Teachers' choice and learners' preference of corrective feedback types. Language Awareness, 17(1), 78-93.

Zacharias, T. 2007. Teacher and student attitudes towards feedback. RELC Journal 38: 38-52. 